Supplement to

\title{
Base cations in the soil bank. Non-exchangeable pools may sustain centuries of net loss to forestry and leaching.
}

Nicholas P. Rosenstock et al.

5 Correspondence to: Nicholas P. Rosenstock (rosenstockn@gmail.com)

\section{Supplementary methods.}

\subsection{Soil sampling, extraction methods and chemical analyses}

At the Swedish integrated monitoring catchment Kindla, soil samples were collected in October 2012 from three manually excavated pits located along a ca $150 \mathrm{~m}$ long hydrological gradient (ca $20 \mathrm{~m}$ elevation difference), representing a groundwater recharge area (Podzol; "upslope"), a groundwater discharge area (Regosol; "downslope”), and an intermediate zone (Regosol; "midslope"), The sampling was conducted according to Cools and de Vos (2010). Discrete samples were taken from the E, B, and C horizons according to Table S1. Within one day of sampling, soils were sieved (2 $\mathrm{mm}$ ) and dried at $40^{\circ} \mathrm{C}$. Soil texture was determined according to the pipette method (Cools and de Vos, 2010), while carbon and nitrogen were determined by dry combustion with CNS analyzer (LECO CNS-1000). On sub-samples from each soil layer, base cations were extracted with $\mathrm{H}_{2} \mathrm{O}, \mathrm{BaCl}_{2}(\mathrm{Cools}$ and de Vos, 2010), ammonium lactate (Egnér et al., 1960), $\mathrm{HCl}$ (Andrist-Rangel et al. 2013) and aqua regia (ISO 11466:1995) solutions according to Table S1. The concentrations of base cations $\mathrm{Ca}, \mathrm{K}, \mathrm{Mg}$, and $\mathrm{Na}$ in soil extracts were determined by ICPAES (ISA Jobin Yvon JY24). The O horizon was not included in the SoilTrEc project, but the organic horizon of the same hillslope was in October 2006 sampled within the EU Life+ project BioSoil (De Vos and Cools, 2011) and extracted with 0.1 $\mathrm{M} \mathrm{BaCl}_{2}$ and Aqua Regia as described in Table S1. The SoilTrEC and BioSoil soil sampling pits are not identical, but forest age, structure and management history, hydrologic gradient, soil types, humus layer thickness and bulk density are identical. Hence, we have used the BioSoil extraction data for estimating these two base cations pools in the organic horizon.

\subsection{Base cation fluxes for mass balance}

Total deposition (wet + dry) and biomass uptake of base cations were taken from Zetterberg et al. (2014; also used by

25 McGivney et al., 2019). The effects of varying canopy interception during each forest rotation were taken into account for the total deposition estimates.

The tree biomass development during the forest rotation was estimated by using the Swedish forest growth model ProdMod (version 2.2) and the biomass BC uptake was calculated for stem-only (SO) and whole-tree (WT) harvest scenarios (Zetterberg et al. 2014, McGivney et al. 2019). Biomass uptake of base cations was estimated over two 65-year rotation periods of Norway spruce (Picea abies, L.), following an assumed clear-cutting of a non-managed Norway spruce forest in 2020. Stem-only harvest accounted for removal of stems and bark, and assumed removal of 37\%, 39\%, 37\%, and $37 \%$ of total aboveground stores of Ca, K, Mg (Nilsson et al., 2018), and Na (Iwald et al., 2013), respectively. The WT harvest scenario accounted for removal of logging residues, stumps and coarse roots assuming that 70\%, 76\%, 70\%, and $70 \%$ of total aboveground stores of $\mathrm{Ca}, \mathrm{K}, \mathrm{Mg}$, and $\mathrm{Na}$ were removed. The remainder was assumed to be left behind in the forest according to standard harvest practice (Nilsson et al., 2018). In addition, the root + stump biomass removals were assumed to be equivalent to an additional $21 \%, 25 \%, 15 \%$, and $20 \%$ of total aboveground stores of $\mathrm{Ca}, \mathrm{K}, \mathrm{Mg}$, and $\mathrm{Na}$, based on biomass mass ratios and nutrient contents from Zetterberg et al. (2014). 
Leaching estimates were calculated based on the $\mathrm{BC}$ concentrations in soil solution collected with suction lysimeters (P80 cheramic cups, cut-off ca $1 \mu \mathrm{m}$ ) from the B horizon (30-40 cm soil depth) from each position along the

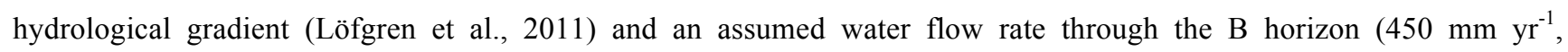
McGivney et al., 2019). The calculated BC leaching rates were then compared to measured whole catchment base cation

5 export rates obtained from this catchment (Löfgren et al., 2011) and for all four base cations, whole catchment export rates fell within the range of calculated leaching rates calculated for each plot. Given the accumulated influx of groundwater from uphill into the lower Regosol (in the groundwater discharge zone), we may thus expect that leaching is somewhat underestimated for the lower Regosol.

Mineral weathering rates were taken from McGivney et al. (2019), which used the PROFILE model to calculate

10 weathering rates. PROFILE is a mechanistic kinetics model that calculates the release rates of $\mathrm{Ca}, \mathrm{K}, \mathrm{Mg}$, and $\mathrm{Na}$ in each soil horizon as a function of the minerals present, their surface area and soil solution chemistry (Warfvinge and Sverdrup, 1993). Soil minerology was derived from total soil elemental contents from complete soil chemical digestion using the A2M model (Posch and Kurz, 2007) and soil solution chemistry was modelled with the Husby Dynamic MINTEQ model. (Gustafsson, 2018)

\section{$15 \quad 1.3$ Microbial biomass contents}

A conservative estimate of microbial biomass pools was made by assuming that microbial biomass carbon constituted $1 \%$ of soil organic carbon (Vance et al., 1987; Diaz-Raviña et al., 1987; Yang et al., 2010), and that the ratios of base cations in microbial biomass to microbial biomass carbon were C:Ca, 104; C:K, 21.1; C:Mg, 621; C:Na, 1000 (Anderson and Domsch, 1980; Diaz-Raviña et al., 1993; Wang et al., 2015).

25 Table S1. Base cation extraction methods used on soils collected 16 October 2012 within the Kindla catchment (SoilTrec project).

\begin{tabular}{cccccc} 
Extractant & Extractant chemistry & $\begin{array}{c}\text { Soil } \\
\text { mass }(\mathrm{g})\end{array}$ & $\begin{array}{c}\text { Extractant } \\
\text { volume }(\mathrm{ml})\end{array}$ & $\begin{array}{c}\text { Extraction } \\
\text { time }\end{array}$ & Extraction temperature \\
\hline $\mathrm{H} 2 \mathrm{O}$ & Distilled $\mathrm{H}_{2} \mathrm{O}$ & 5 & 50 & $2 \mathrm{~h}$ & $\mathrm{Ca} 20^{\circ} \mathrm{C}$ \\
$\mathrm{BaCl} 2$ & $0.1 \mathrm{M} \mathrm{BaCl}_{2}$ & 2,5 & 30 & $2 \mathrm{~h}$ & $\mathrm{Ca} 20^{\circ} \mathrm{C}$ \\
Ammonium & $0.01 \mathrm{M} \mathrm{Ammonium}$ & 3 & 60 & 1,5 & $\mathrm{Ca} 20^{\circ} \mathrm{C}$ \\
lactate $(\mathrm{AL})$ & lactate $\mathrm{pH}=3.75$ & & & & $100^{\circ} \mathrm{C}$ \\
$\mathrm{HCl}$ & $0.2 \mathrm{M} \mathrm{HCl}$ & 2 & 50 & $2 \mathrm{~h}$ & $100^{\circ} \mathrm{C}$ \\
$\mathrm{HCl}$ & $0.5 \mathrm{M} \mathrm{HCl}$ & 2 & 50 & $2 \mathrm{~h}$ & $16 \mathrm{~h} \mathrm{ca} 20^{\circ} \mathrm{C}+$ \\
Aqua regia & $12 \mathrm{M} \mathrm{HCl}, 16 \mathrm{M}$ & 3 & 27 & $16+2$ & $\left.2 \mathrm{~h} 120^{\circ} \mathrm{C} \mathrm{(reflux}\right)$
\end{tabular}

